\title{
Chemistry-Climate Connections - Interaction of Physical, Dynamical, and Chemical Processes in Earth Atmosphere
}

\author{
Martin Dameris ${ }^{1}$ and Diego Loyola ${ }^{2}$ \\ 1 Deutsches Zentrum für Luft- und Raumfahrt, Institut für Physik der Atmosphäre \\ 2Deutsches Zentrum für Luft- und Raumfahrt, Institut für Methodik der Fernerkundung \\ Oberpfaffenhofen, \\ Germany
}

\section{Introduction}

The climate system of the Earth atmosphere is affected by a complex interplay of dynamical, physical and chemical processes acting in the troposphere (atmospheric layer reaching from the Earth surface up to about $12 \mathrm{~km}$ height) and the Middle Atmosphere, i.e. the stratosphere (from about 12 to $50 \mathrm{~km}$ ) and the mesosphere (from 50 to $100 \mathrm{~km}$ ). Moreover, mutual influences between these atmospheric layers must be taken into account to get a complete picture of the Earth climate system. An outstanding example which can be used to describe some of the complex connections of atmospheric processes is the evolution of the ozone layer in the stratosphere and its interrelation with climate change.

The stratospheric ozone layer (located around 15 to $35 \mathrm{~km}$ ) protects life on Earth because it filters out a large part of the ultraviolet (UV) radiation (wavelength range between $100 \mathrm{~nm}$ and $380 \mathrm{~nm}$ ) which is emitted by the sun. The almost complete absorption of the energyintensive solar UV-B radiation $(280-320 \mathrm{~nm})$ is especially important. UV-B radiation particularly affects plants, animals and people. Increased UV-B radiation can, for example, adversely impact photosynthesis, cause skin cancer and weaken the immune system. In addition, absorption of solar UV radiation by the stratospheric ozone layer causes the temperature of the stratosphere to increase with height, creating a stable layer that limits strong vertical air movement. This plays a key role for the Earth's climate system. Approximately $90 \%$ of the total ozone amount is found in the stratosphere. Only $10 \%$ is in the troposphere; ozone concentrations in the troposphere are much lower than in the stratosphere.

Data derived from observations (measurements from satellites and ground-based instruments) and respective results from numerical simulations with atmospheric models are used to describe and explain recent alterations of the dynamics and chemistry of the atmosphere.

Since the beginning of the 1980ies in each year the ozone hole develops over Antarctica during spring season (i.e. September to November), showing a decrease in the total amount of ozone of up to 70\% (see Figure 4). Especially in the lower stratosphere (about $15-25 \mathrm{~km}$ altitude), ozone is almost completely destroyed during this season. Relatively shortly after the discovery of the ozone hole, the extreme thinning of the ozone layer in the south-polar 
stratosphere was explained as a combination of special meteorological conditions and changed chemical composition induced by industrially manufactured (anthropogenic) chlorofluorocarbons (CFCs) and halons.

\subsection{Ozone chemistry}

In the atmosphere, ozone $\left(\mathrm{O}_{3}\right)$ is produced exclusively by photochemical processes. Ozone formation in the stratosphere is initiated by the photolysis of molecular oxygen $\left(\mathrm{O}_{2}\right)$. This produces two oxygen atoms $(\mathrm{O})$ which recombine with molecular oxygen to form ozone. Since ozone is created by photochemical means, it is mainly produced in the tropical and subtropical stratosphere, where sunshine is most intensive throughout the year. At the same time, the ozone molecules formed in this way are destroyed again by the photolysis of ozone and by reaction with an oxygen atom. These reactions form the basis of stratospheric ozone chemistry, the so-called Chapman mechanism (Chapman, 1930). But if stratospheric ozone amounts are determined via this simple reaction system and the known rate constants and photolysis rates, the results obtained are about twice as high as the measured values. Since the early 1950ies, it has been known that fast so-called catalytic cycles reduce the determined ozone amounts to the observed values. By the early 1970ies, the catalysts had been identified as the radical pairs $\mathrm{OH} / \mathrm{HO}_{2}$ and $\mathrm{NO} / \mathrm{NO}_{2}$, which are formed from water vapour $\left(\mathrm{H}_{2} \mathrm{O}\right)$ and nitrous oxide $\left(\mathrm{N}_{2} \mathrm{O}\right)$ respectively (Bates and Nicolet, 1950; Crutzen, 1971; Johnston, 1971). In the mid-1970ies, the radical pairs $\mathrm{Cl} / \mathrm{ClO}$ (from CFCs) and $\mathrm{Br} / \mathrm{BrO}$ (from halons) were identified as further significant contributors (Molina and Rowland, 1974; Wofsy et al., 1975). The important point is that a catalyst can take part in the reaction cycle several thousand times and therefore is very effective in destroying ozone molecules. The increased occurrence of CFCs and halons due to anthropogenic emissions has significantly accelerated stratospheric ozone depletion cycle over recent decades, triggering a negative stratospheric ozone trend which is most obvious in the Southern polar stratosphere during spring time where the ozone hole is found. In the troposphere, CFCs and halons are mostly inert. Over time (several years), they are transported into the stratosphere. Only there they are photolysed and converted into active chlorine or bromine compounds.

In particular, ozone is depleted via the catalytic $\mathrm{Cl} / \mathrm{ClO}$-cycle in polar spring. However, the kinetics of these processes are very slow, because the amount of UV radiation is limited due to the prevailing twilight conditions. In the polar stratosphere, it is mainly chemical reactions on the surface of stratospheric ice particles that are responsible for activating chlorine (and also bromine) and then driving ozone depletion immediately after the end of polar night (Solomon et al., 1986). In the very cold lower polar stratosphere, polar stratospheric clouds (PSCs) form during polar night (Figure 1). PSCs develop at temperatures below about $195 \mathrm{~K}\left(=-78^{\circ} \mathrm{C}\right)$ where nitric acid trihydride crystals form (NAT, $\mathrm{HNO}_{3} \cdot 3 \mathrm{H}_{2} \mathrm{O}$ ). Under the given conditions in the lower stratosphere ice particles develop at temperatures below approx. $188 \mathrm{~K}\left(=-85^{\circ} \mathrm{C}\right)$. Due to different land-sea distributions on the Northern and Southern Hemisphere, the lower stratosphere over the south pole cools significantly more in winter (June - August) than the north polar stratosphere (December February) (see Section 1.2). The climatological mean of polar winter temperatures of the lower Arctic stratosphere is around $10 \mathrm{~K}$ higher than that of the lower Antarctic stratosphere. While the Antarctic stratosphere reaches temperatures below PSC-forming temperatures for several weeks every year, there is a pronounced year-on-year variability in the north polar stratosphere: relatively warm winters, where hardly any PSCs develop are 
observed, as well as very cold winters, with conditions similar to that of Antarctica. This means that expansive PSC fields develop in the Antarctic stratosphere every year, but are seldom seen over the Arctic (see Section 2.1). A detailed description of chemical processes affecting ozone is given by Dameris (2010).

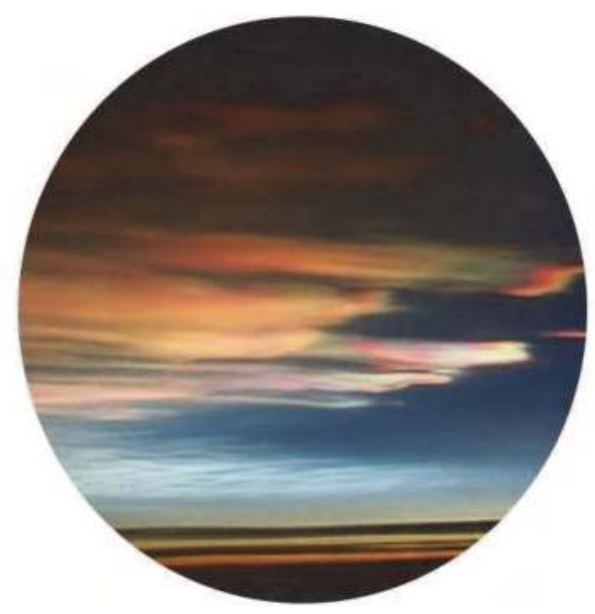

Fig. 1. Polar stratospheric clouds over Finland. The picture was taken on January 26, 2000 from the DLR research aircraft Falcon.

\subsection{Importance of stratospheric dynamics}

Since the 1990ies it became obvious that the ozone layer was not just getting thinner over Antarctica, but over many other regions, too, although to a lesser extent (see Figure 5). Many observations from satellite instruments and ground based techniques (incl. radiosondes) have shown a clear reduction of the amount of stratospheric ozone, e.g. in middle geographical latitudes (about $30^{\circ}-60^{\circ}$ ) of both hemispheres. From that time on observational evidences and the actual state of understanding have been reviewed in WMO/UNEP Scientific Assessments of Ozone Depletion (WMO, 1992; 1995; 1999; 2003; 2007; 2011). It turned out that the thickness of the stratospheric ozone layer is not solely controlled by chemical processes in the stratosphere. Physical and dynamic processes play an equally important role.

The polar stratosphere during winter is dominated by strong west wind jets, the polar vortices. Due to the different sea-land distribution in the Northern and Southern Hemisphere these wind vortices develop differently in the two hemispheres. Large-scale waves with several hundreds kilometres wavelength are generated in the troposphere, for example during the overflow of air masses over mountain ridges. These waves propagate upward into the stratosphere and affect the dynamics there including the strength of the polar wind jets. The polar vortex in the Southern Hemisphere is less disturbed and therefore the mean zonal wind speed is stronger than in the Northern Hemisphere. In the Southern Hemisphere this leads to a stronger isolation of stratospheric polar air masses in winter and a more pronounced cooling of the polar stratosphere during polar night (see Section 1.1). 
Additionally, atmospheric trace gas concentrations are affected by air mass transports, which are determined by wind fields (wind force and direction). The extent to which such a transport of trace gases takes place depends on the lifetime of the chemical species in question. Only if the chemical lifetime of a molecule is longer than respective dynamical timescales, the transport contributes significantly to the distribution of the chemical substance. For example, in the lower stratosphere the chemical lifetime of ozone is long enough that transport processes play a key role in geographical ozone distribution there. At these heights, ozone can be transported to latitudes where, photochemically, it is only produced to an insignificant extent. In this way, ozone generated at tropical (up to about $15^{\circ}$ ), sub-tropical (about $15^{\circ}-30^{\circ}$ ) and middle latitudes is transported particularly effectively in the direction of the winter pole (i.e. towards the north polar region from December to February and towards the south polar region from June to August), due to large-scale meridional (i.e. north-south) circulation. There, it is mixed in with the local air. This leads to an asymmetric global ozone distribution with peaks at higher latitudes during the corresponding spring months and not over the equator (see Figures 7 and 8). At higher stratospheric latitudes, it is thus particularly difficult to separate chemical influences on ozone distribution (ozone depletion rates) from the changes caused by dynamic processes.

With respect to climate change due to enhanced greenhouse gas concentrations (i.e. in particular carbon dioxide, $\mathrm{CO}_{2}$, methane, $\mathrm{CH}_{4}$, and nitrous oxide, $\mathrm{N}_{2} \mathrm{O}$ ) caused by human activities, it is expected that temperatures in the troposphere will further increase (IPCC, 2007) and that they will further decrease in the stratosphere due to radiation effects (Chapter 4 in WMO, 2011). Since the reaction rates of many chemical reactions are directly depending on atmospheric temperature, climate change will directly influence chemical processes and therefore the amount and distribution of chemical substances in Earth atmosphere. Moreover, changes in atmospheric temperature and temperature gradients are modifying dynamic processes that drive the circulation system of the atmosphere. This would result in changing both, the intensity of air mass transports and the transportation routes, with possible long-term consequences for the atmospheric distribution of radiatively active gases, including ozone. Changes in distribution of the climate-influencing trace gases in turn affect the Earth's climate.

\section{Measuring ozone with satellite instruments and numerical modelling}

Since many years ozone distribution in the stratosphere is observed by ground-based and satellite instruments (see Section 2.1). In particular measurements from space help to get a global view of the state of the stratospheric ozone layer and its temporal evolution including short-term fluctuations and long-term changes (i.e. trends). An outstanding task is to combine multi-year observations derived from different sensors flown on different satellites in a way that at the end one gets consistent and homogeneous data products which enable solid scientific investigations of processes causing the basic state of the atmosphere and its variability. In addition to a detailed analysis of existing measurements, numerical models of the atmosphere are used to reproduce as best as possible recent atmospheric conditions and the modulation in space and with time. Sensitivity studies help to identify those processes most relevant to describe climatological mean atmospheric conditions as well as spatial and temporal changes. For example, changes in climate, the temporal evolution of the ozone layer and the connections between them are simulated by atmospheric models which consider all known and relevant dynamical, physical as well as chemical processes (see 
Section 2.2). In such numerical studies, it is important to consider natural processes and their variations, as well as human activities relevant to atmospheric processes. A comprehensive evaluation of data derived from numerical model simulations with respective observations helps to identify the strength and weaknesses of the applied model systems which to a great part reflect the current state of the knowledge about processes acting in Earth atmosphere (see Section 3). A good understanding of all crucial processes is necessary, for example, for reliably estimating the future development of the ozone layer (Section 4). In this context, alterations in atmospheric processes due to climate change must be considered.

\subsection{Observations from satellite}

Satellite remote sensing of ozone started in 1970 with the Backscatter Ultraviolet Spectrometer (BUV) onboard the NASA satellite Nimbus-4. The first Total Ozone Mapping Spectrometer (TOMS) was launched in 1978 onboard the Nimbus-7 satellite and was followed by a series of Solar Backscatter UV Instrument (SBUV). TOMS measured the total column of atmospheric ozone content whereas the SBUV measured height resolved stratospheric ozone profiles. The last TOMS instrument operated until 2007, the Ozone Mapper Profiler Suite (OMPS) to be launched in 2011 will continue this data record.

The European contribution to satellite base measurements of atmospheric composition started with the Global Ozone Monitoring Experiment (GOME) sensor onboard the ESA satellite ERS-2 launched in 1995. GOME measured not only ozone (total column, profiles and tropospheric column) but also a number of atmospheric composition gases like nitrogen dioxide, sulphur dioxide, bromine monoxide, water vapour, formaldehyde, chlorine dioxide, glyoxalin as well as clouds and aerosols (see Burrows et al., 1999). The GOME data record is continued with the SCIAMACHY sensor onboard the ESA satellite ENVISAT launched in 2002, with the Dutch sensor OMI onboard the NASA satellite AURA launched in 2004, and with the GOME-2 sensor onboard the EUMETSAT satellite MetOp-A launched in 2006. This 16 years data record will be continued with the GOME-2 sensors on the EUMETSAT satellites MetOp-B (to be launched in 2012) and MetOp-C (to be launched in 2017). The ESA's Sentinel 5 precursor mission (to be launched in 2015), Sentinel 4 and Sentinel 5 with further extend this data record with similar sensor systems in the next decades.

Remote Sensing in the UV/VIS spectral range between $280 \mathrm{~nm}$ and $450 \mathrm{~nm}$ is based on measurements of backscattered radiation from the Earth-atmosphere system. The Differential Optical Absorption Spectroscopy (DOAS) fitting technique is used to derive trace gas slant column amounts along the viewing path of the GOME-type instruments. The spectral structure of ozone in the Huggings bands (Figure 2) measured by a satellite sensor is compared to laboratory measurements to quantify the ozone content on the atmosphere. The slant columns determined with DOAS are finally converted to geometry-independent vertical column amounts through division by appropriate air mass factors (Van Roozendael et al., 2006) which result from radiative transfer calculations (see Figure 3). Air mass factors describe the enhanced absorption of a given trace gas due to slant paths of incident light in the atmosphere. The ozone retrieval must also take into account the influence of clouds and other atmospheric effects (Loyola et al., 2011).

Satellite total ozone measurements are systematically compared with ground-based measurements and the differences are typically lower than $1 \%$. Nevertheless satellite ozone data from different instruments may show spatial and temporal differences due to sensor 

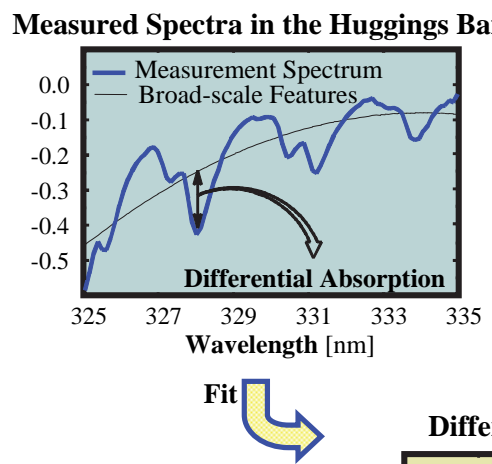

\section{Absorption Cross-section $\left[10^{19} \mathrm{~cm}^{2} \mathrm{~mol}^{-1}\right]$}

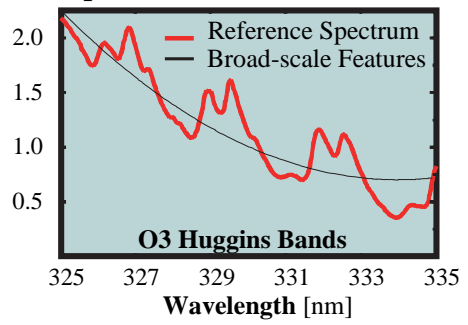

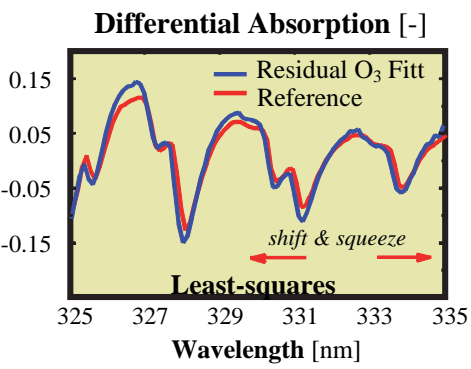

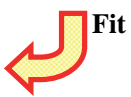

Fig. 2. Schematically representation of the DOAS principle used for the retrieval of ozone content from the Huggings bands between $325 \mathrm{~nm}$ and $335 \mathrm{~nm}$. The differential structure of satellite measurements (top left) and laboratory measurements (top right) are fitted together (low panel) to determine the current ozone amount.

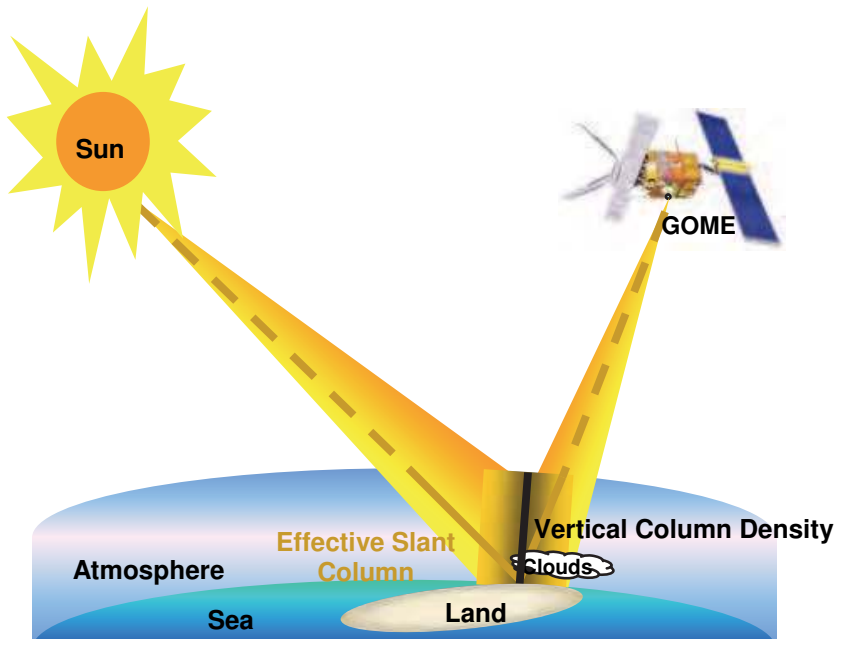

Fig. 3. The satellite measured ozone slant column (brown path) is converted to viewing geometry independent vertical column of ozone (black path). 
specific characteristics and drifts. Therefore some corrections are needed before merging data from different satellites to create long-term homogenous climate data records that can be used for ozone trend studies. In this chapter we use the merged satellite TOMS/OMI data record (Stolarski et al., 2006) starting in 1979 and the merged GOME/SCIAMACHY/GOME-2 data record (Loyola et al., 2009) starting in 1995.

An ozone hole is said to exist when the total ozone column sinks to values below $220 \mathrm{DU}$, which is around 30\% under the norm. Dobson Units are column densities - a measure of the total amount of ozone in a column over a specific place. At standard temperature and pressure $\left(1000 \mathrm{hPa}, 0^{\circ} \mathrm{C}\right)$, a $0.01-\mathrm{mm}$ thick ozone layer corresponds to $1 \mathrm{DU}$. A $300-\mathrm{DU}$ thick ozone layer at the Earth's surface would thus correspond to a pure ozone column of $3 \mathrm{~mm}$. Figure 4 shows the evolution of ozone hole as measured by the TOMS sensor onboard the Nimbus 7 satellite between 1979 to 1992, TOMS data from the Meteor satellite between 1993 to 1994, GOME data from the ERS-2 satellite between 1995 and 2002, SCIAMACHY data from the ENVISAT satellite between 2003 and 2006, and GOME-2 data from the MetOp-A satellite between 2007 and 2010. The average ozone from October $1^{\text {st }}$ to $3^{\text {rd }}$ is plotted for all the years with the exception of 1993 and 2002 where data from September 23rd to 25th are used. In 1993 no TOMS data were available at the beginning of October and in 2002 the data from September are plotted to show the atypical split of the ozone hole due to the unusual meteorological conditions in the stratosphere occurring only in 2002.

Corresponding results for Northern Hemisphere spring time conditions are presented in Figure 5. There, average total ozone column from March $25^{\text {th }}$ to $27^{\text {th }}$ is plotted for all years between 1979 and 2011 except 1995 where no satellite data is available. Obviously the ozone depletion is not as strong as in the Southern Hemisphere and the trend towards lower ozone amount is much less visible. The interannual variability is high which can be explained by the variability of stratospheric dynamics (see Sections 1.1 and 1.2). Nevertheless, most clearly seen in years like 1997 and 2011, the dynamic situation of the Arctic stratosphere can be very similar to the Antarctic, i.e. showing a well-pronounced and undisturbed polar vortex in winter with temperatures low enough to form PSCs in large extent. Other years which also show a significant reduction of total ozone in northern spring are 1990, 1993, 1996, and 2007. On the other hand, in years like 1998 and 2010 when stratospheric temperatures are enhanced due to disturbed stratospheric dynamic conditions, total ozone values are much higher. It is also obvious that total ozone values at low latitudes (i.e. tropical and sub-tropical regions) are naturally low.

\subsection{Simulations with chemistry-climate models}

Chemistry-climate models (CCMs) are numerical tools which are used to study connections between atmospheric chemistry and climate (Figure 6). They are composed of two basic modules: An Atmospheric General Circulation Model (AGCM) and a Chemistry Model.

An AGCM is a three-dimensional model describing large-scale (i.e. spatial resolution of a few hundred $\mathrm{km}$ ) physical, radiative, and dynamical processes in the atmosphere over years and decades. It is used to study changes in natural variability of the atmosphere and for investigations of climate effects of radiatively active trace gases (greenhouse gases) and aerosols (i.e. natural and anthropogenic particles in the atmosphere), along with their interactions and feedbacks. Usually, AGCM calculations employ prescribed concentrations of radiatively active gases, e.g. $\mathrm{CO}_{2}, \mathrm{CH}_{4}, \mathrm{~N}_{2} \mathrm{O}, \mathrm{CFCs}$, and $\mathrm{O}_{3}$. Changes of water vapour $\left(\mathrm{H}_{2} \mathrm{O}\right)$ concentrations due to the hydrological cycle are directly simulated by an AGCM. The 

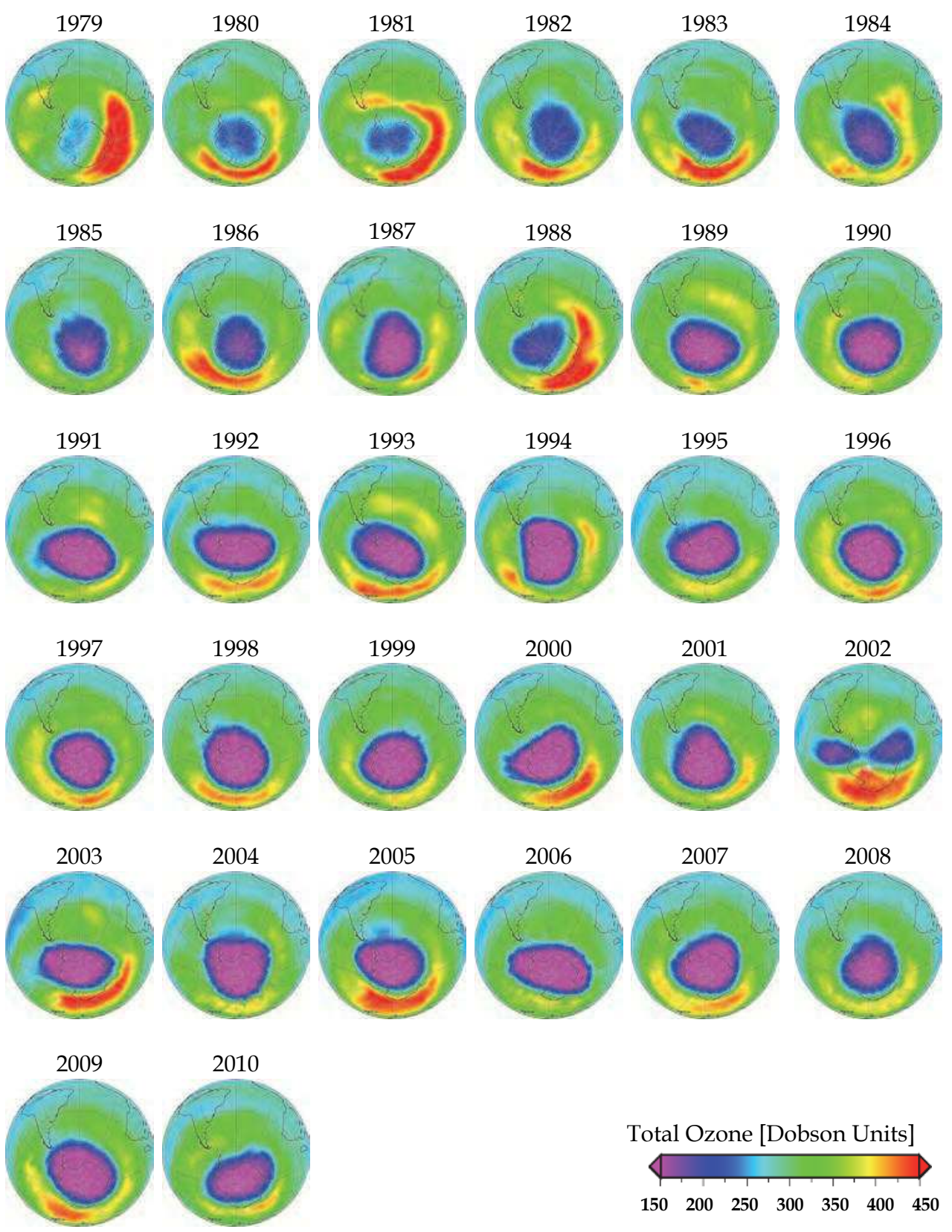

Total Ozone [Dobson Units]

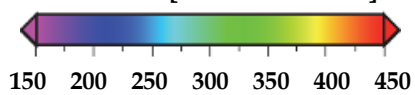

Fig. 4. Evolution of the ozone hole derived from satellite measurements in early October from 1979 until 2010. The purple area over the South Polar Region indicates the area of the ozone hole (see text). 

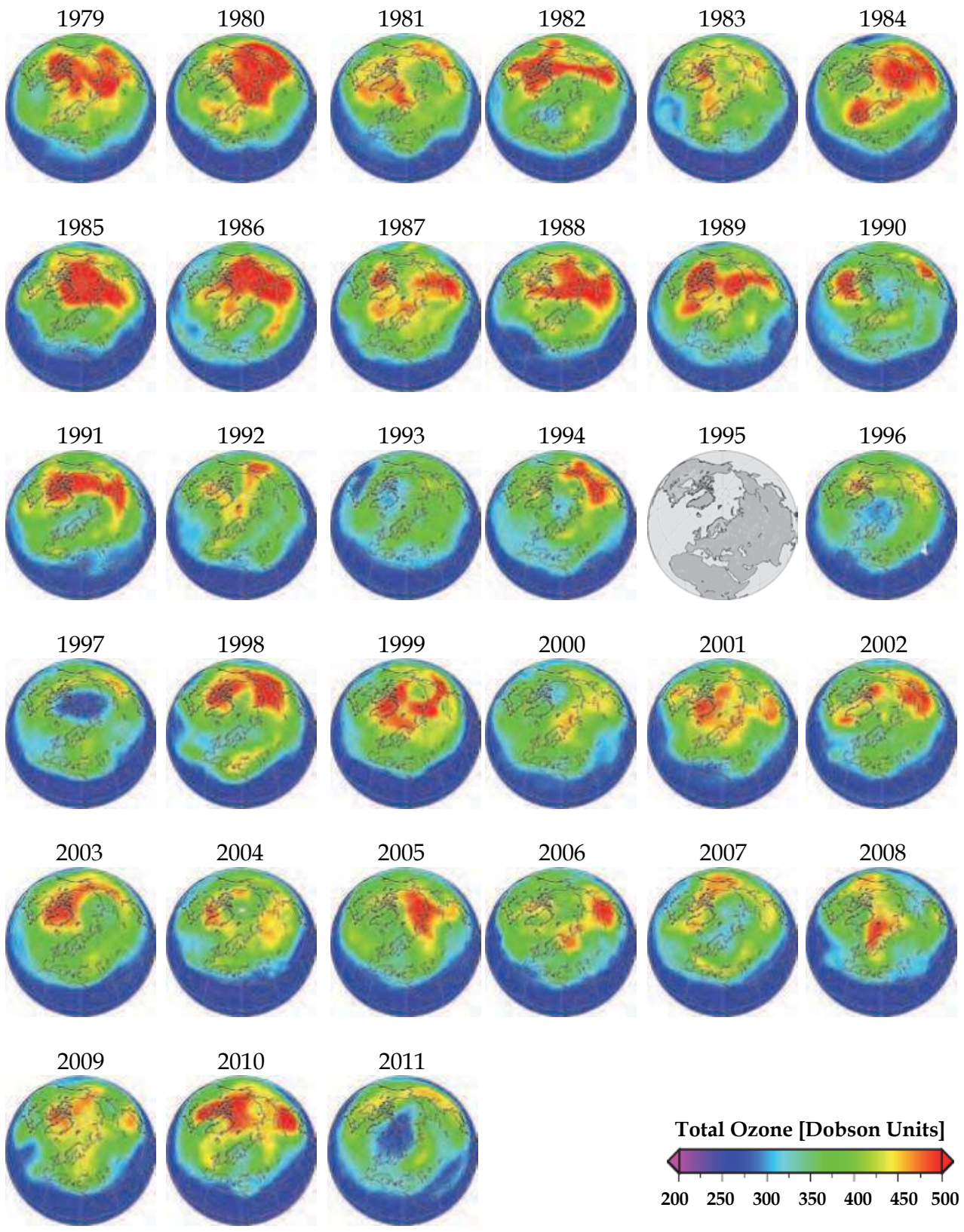

Fig. 5. As Figure 4, but for the Northern Hemisphere and using a different colour scale. Evolution of the ozone derived from satellite measurements in late March from 1979 until 2011 (no data available for 1995, see text). 
temporal development of sea surface temperatures (SSTs) and sea ice coverage are prescribed in these models. The chosen boundary conditions for concentrations of radiatively active gases and SSTs (incl. sea ice) represent a specific period of time, e.g. some years or decades.

In a CCM, i.e. an AGCM interactively coupled to a model describing in detail atmospheric chemistry, the simulated concentrations of the radiatively active gases are used in the calculations of heating rates (e.g. due to the absorption of short-wave solar radiation) and cooling rates (e.g. due to the emission of long-wave infrared radiation). Changes in the abundance of these gases due to chemistry and advection influence heating and cooling rates and, consequently, variables describing atmospheric dynamics such as temperature and wind. This gives rise to a dynamical-chemical coupling in which the chemistry influences the dynamics (via radiative heating and cooling) and vice versa (via temperature and advection). As an example, ozone represents the dominant radiative-chemical feedback in the stratosphere. Simulations with CCMs also consider gradual changes in concentrations of radiatively active gases and other boundary conditions (e.g., emissions). The temporal development of source gas emissions are prescribed for a specific episode (years to decades).

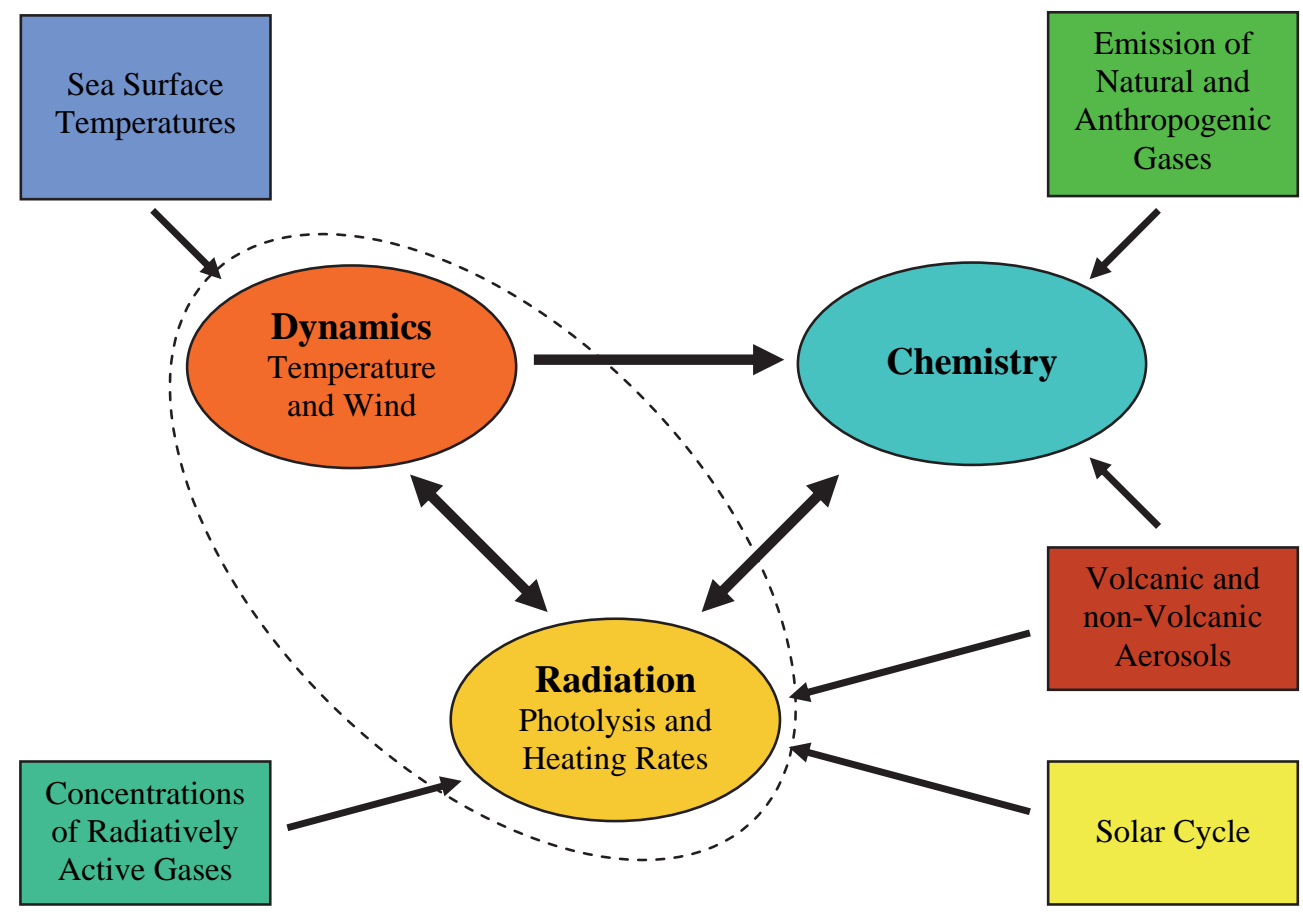

Fig. 6. Schematic of a Chemistry-Climate Model (CCM). The core of a CCM (oval symbols) consists of an atmospheric general circulation model (AGCM; i.e. dynamics and radiation part) that includes calculation of the heating and cooling rates and a detailed chemistry module. They are interactively coupled. Arrows indicate the direction of effect. Rectangular boxes denote external forcing. 
As an example, in the following a brief description of the CCM E39CA is presented providing some useful details to better understand how such a model system works and respective simulations are performed. E39CA consists of the dynamic part E39 and the chemistry module CHEM. "E39" is an AGCM, based on the circulation model ECHAM4 (Roeckner et al., 1996). It has a vertical resolution of 39 levels from the Earth surface up to the top layer centred at $10 \mathrm{hPa}$ (Land et al., 2002). The horizontal model grid on which the tracer transport, model physics and chemistry are calculated, has a mesh size of approximately $3.75^{\circ} \cdot 3.75^{\circ}$ (latitude, longitude). The chosen time step for model integration is 24 minutes. The chemistry module " $\mathrm{C}$ " (Steil et al., 1998) is based on a family concept which combines related chemical constituents with short lifetimes (shorter than that of the dynamics or the model time-step used) into one family with a life-time larger than the timestep. " $\mathrm{C}$ " includes stratospheric homogeneous and heterogeneous ozone chemistry and the most relevant chemical processes for describing the tropospheric background chemistry with 107 photochemical reactions, 37 chemical species and four heterogeneous reactions on PSCs and on sulphate aerosols. Heating and cooling rates and photolysis rates are calculated on-line from the modelled distributions of the radiatively active gases $\mathrm{O}_{3}, \mathrm{CH}_{4}, \mathrm{~N}_{2} \mathrm{O}, \mathrm{H}_{2} \mathrm{O}$ and CFCs, and the actual cloud distribution.

In the following some boundary conditions of an E39CA model simulation are described covering the years from 1960 to 2050 (simulation "R2"). The model simulation considers various natural and anthropogenic forcings like the 11-year activity cycle of the sun with varying intensity of solar radiation (particularly in the ultraviolet which affects ozone chemistry), the quasi-biennial oscillation (QBO) of tropical zonal winds in the lower stratosphere (i.e. the direction of the zonal wind is alternating between west and east with a mean period of 28 months; see Baldwin et al., 2001), chemical and direct radiative effects of gases and aerosols (i.e. particles) emitted during major volcanic eruptions, and the increase in greenhouse gas concentrations. R2 is a simulation performed to assess the past and future evolution assuming a consistent set of boundary conditions which are partly based on observations (for the past) and on particular assumptions for future developments. For example, the future concentrations of long-lived greenhouse gases $\left(\mathrm{CO}_{2}, \mathrm{CH}_{4}\right.$, and $\left.\mathrm{N}_{2} \mathrm{O}\right)$ are based on a 'business as usual' scenario (i.e. the A1B future scenario described in IPCC, 2001); future concentrations of ozone depleting substances follow the A1 scenario prescribed in WMO (2003), e.g. assuming a phase out of the CFCs in the troposphere and stratosphere over the coming decades leading to a continuous decrease of stratospheric chlorine content in future. Moreover, the wind phases of the QBO which were observed in the past are consistently continued. The solar activity signal observed between 1977 and 2007 is continually repeated until 2050. Furthermore, no major volcanic eruptions have been adopted in years up to 2050. Sea surface temperatures (SSTs) and sea ice coverage are prescribed using a continuous dataset derived from the coupled atmosphere-ocean model HadGEM1, provided by the UK Met Office Hadley Centre (Johns et al., 2006). The results from HadGEM1 are taken from a transient simulation with prescribed anthropogenic forcing as observed in the past, and following the SRES-A1B scenario in the future.

More details about the CCM E39CA and the respective assumptions made in the numerical simulation are provided in Stenke et al. (2009) and Garny et al. (2009).

\section{Confronting model results with observations - a basement for predictions}

In this section data derived from multi-year space-borne measurements are compared with respective data derived from simulation $\mathrm{R} 2$ with the CCM E39CA. It should provide some 
insight into current capabilities of numerical modelling of atmospheric processes and how model results are evaluated on the basement of observations. The evaluation of results derived from numerical modelling with observations gives indications about the quality of the applied model which partly reflects our current understanding of atmospheric processes and the cause and effect relationships leading to changes in atmospheric behaviour. The following examples of E39CA are only exemplary; more detailed comparisons including evaluations with other CCMs are provided in the SPARC CCMVal report (2010).

The evolution of the total ozone column in the atmosphere and respective standard deviation (both in Dobson Units, DU) as a function of latitude and time derived from GOME/SCIAMACHY/GOME-2 satellite measurements and the E39CA R2 simulation are presented in Figure 7. Note that the colour bars of the total ozone (upper two figures) are different for satellite and model data to better compare the latitude-time patterns (see discussion below regarding Figure 8 ). It is obvious that the overall variations of total ozone with latitude and time are well reproduced by E39CA.

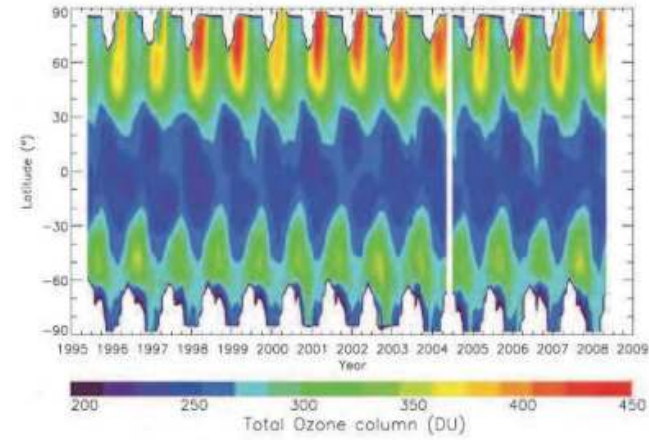

(a) Satellite total ozone

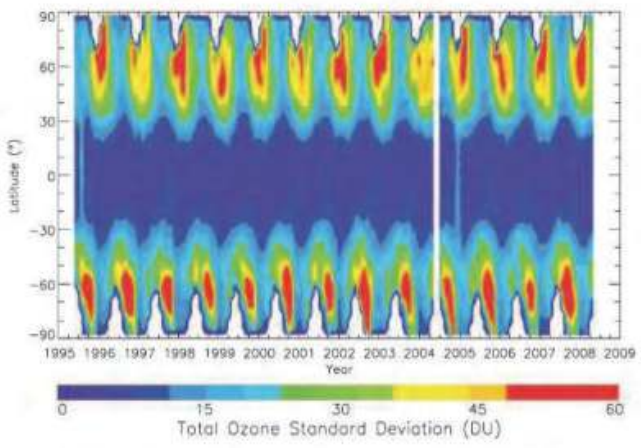

(c) Satellite total ozone standard deviation

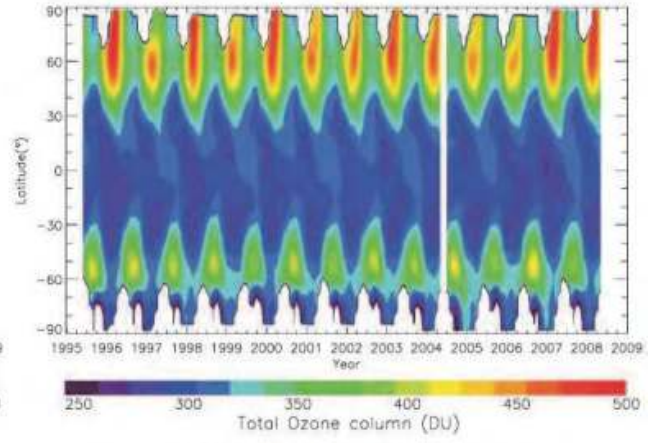

(b) E39C-A total ozone

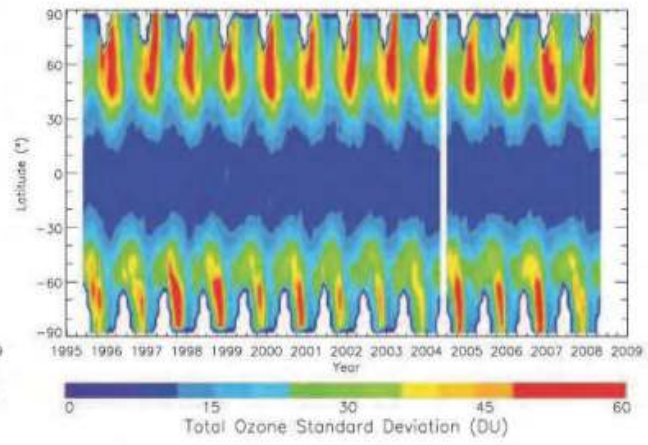

(d) E39C-A total ozone standard deviation

Fig. 7. Latitudinal evolution of total ozone (top) and standard deviation (bottom) from June 1995 to May 2008. GOME/SCIAMACHY/GOME-2 satellite data are presented on the left side $(\mathrm{a}, \mathrm{c})$ and E39CA model on the right side $(\mathrm{b}, \mathrm{d})$. Satellite measurements from April 2004 are not available; the corresponding model data are therefore also neglected (Figure 8 in Loyola et al., 2009). 
The standard deviation of a given quantity (here total ozone in the lower two figures) is a measure for variability of the respective system, describing the range of variability in a specific region and period of time. Again, the agreement between model results and observations is satisfactory, i.e. the spatial and temporal structures are well reproduced. The latter result is important because it indicates that E39CA is able to reproduce adequately the internal variability of stratospheric dynamics and chemistry which is different in the Northern and Southern Hemisphere and the tropics (see Sections 1.1 and 1.2).
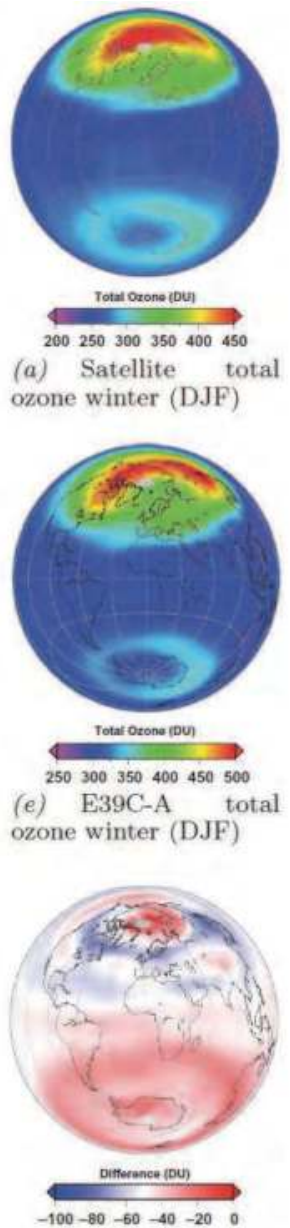

(i) Satellite - E39C-A total ozone difference winter (DJF)
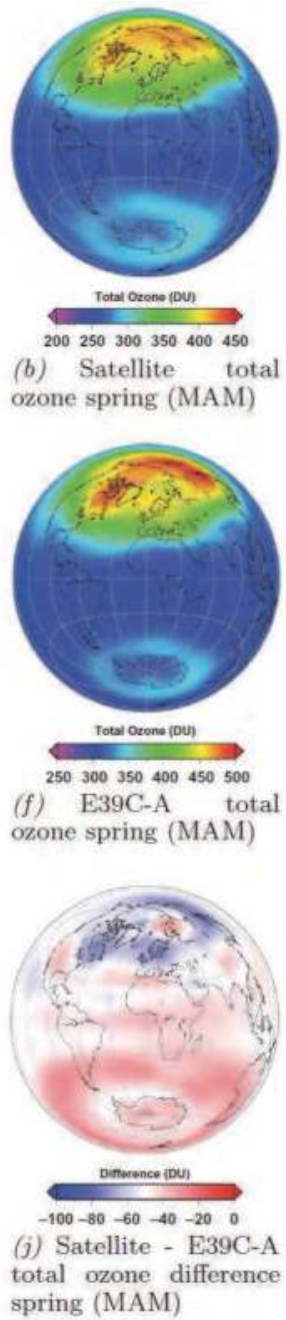
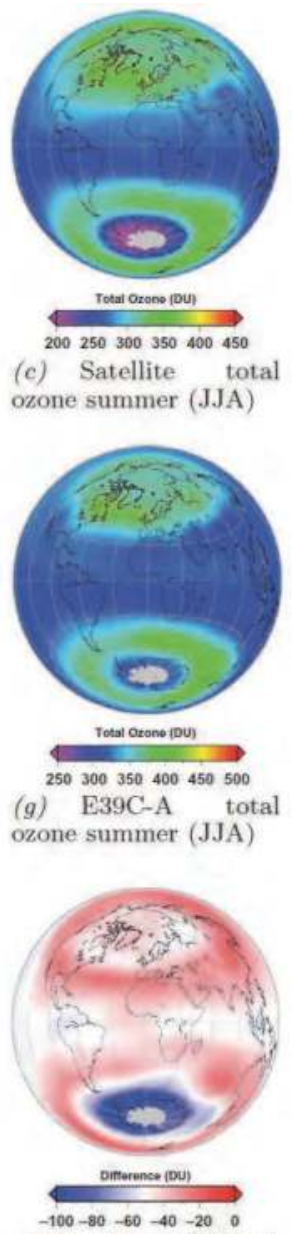

(k) Satellite - E39C-A total ozone difference summer (JJA)
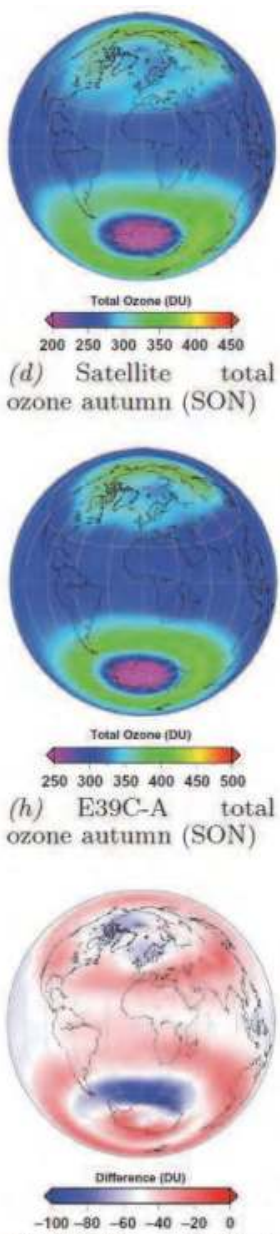

(l) Satellite - E39C-A total ozone difference autumn (SON)

Fig. 8. Seasonal mean values of total ozone (June 1995 to May 2008) from GOME/SCIAMACHY/GOME-2 satellite instruments (top), the E39CA simulation (middle), and the difference between satellite measurements and model results (bottom) (Figure 6 in Loyola et al., 2009). 
Figure 8 provides a more detailed evaluation of the absolute accuracy of total column ozone values as derived from E39CA simulations. Here, seasonal mean values of total ozone derived from satellite instrument measurements and E39CA are once again presented for the time period from June 1995 to May 2008. Please note that the colour bars here are also different for satellite and model data since E39CA total ozone values have a positive bias: A general shift to higher total ozone values is found ranging from about $5 \mathrm{DU}$ in high northern latitudes during winter (DJF) to about $100 \mathrm{DU}$ in high southern latitudes during winter (JJA). This finding indicates that there are still some weaknesses in the applied model system leading to an overall overestimation of total column ozone. Nevertheless, it is obvious that the meridional structure is well represented by E39CA in all seasons. The seasonal changes are well reproduced by the model. Particularly in the Northern Hemisphere, the latitudinal structure compares in a reasonable way. For example, the position of the polar vortex during winter and spring, which is indicated by lower ozone values over Eurasia, is correctly simulated by E39CA. While the Northern Hemisphere is dominated by a clear zonal wave number 1 pattern (i.e. one maximum and one minimum along a latitudinal circle), the distribution of ozone in the Southern Hemisphere has a much more zonally symmetric structure during all seasons which is captured by the model.

In addition to Figure 7, Figure 9 shows seasonal means of the standard deviation of total ozone, again for satellite data and model results. The overall seasonal change and the hemispheric patterns of the standard deviation in the model follow quite well the respective values from observations, but there are some differences in details. For example, in the distribution of the standard deviation in northern winter (DJF) high latitudes show some obvious differences: While in E39CA, the variability is low in the centre of the polar vortex (approximately between northern Europe and the North Pole) and higher in the surroundings, the satellite data show high variability in the vortex centre and a lower standard deviation over North America and eastern Asia. This finding can be explained by the fact that the polar vortex is too stable in E39CA, i.e. the number of minor and major warmings is lower than observed (e.g. Stenke et al., 2009). In the summer hemisphere (DJF in the Southern Hemisphere) the standard deviation is much higher in the model, but the region of maximum variability agrees again well with those derived from observed values. Another clear difference is found in the Southern Hemisphere spring months (SON) indicating a weaker variability in the South Polar Region (see also lower part of Figure 11). This model behaviour is explained by a too cold polar lower stratosphere in E39CA ('cold pole problem') reducing the dynamical variability in this region strongly (Stenke et al., 2009).

The comparisons shown so far were based on climatological and seasonal mean values. They are mainly used to rate the basic state of a numerical model system. Also important is the evaluation of the temporal evolution of an atmospheric quantity. The adequate reproduction of short-term variability and long-term changes, i.e. trends, is another prerequisite for robust assessment of future developments. Some examples are presented in the following section.

\section{Prognostic studies}

As a result of international agreements on protecting the stratospheric ozone layer (Montreal Protocol in 1987 and its amendments), the rapid increase in concentrations of the main CFCs in the troposphere has been stopped. Since the mid-1990ies, a decline in 

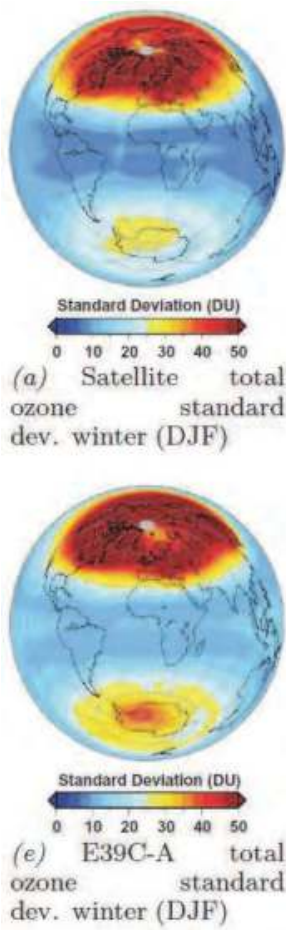
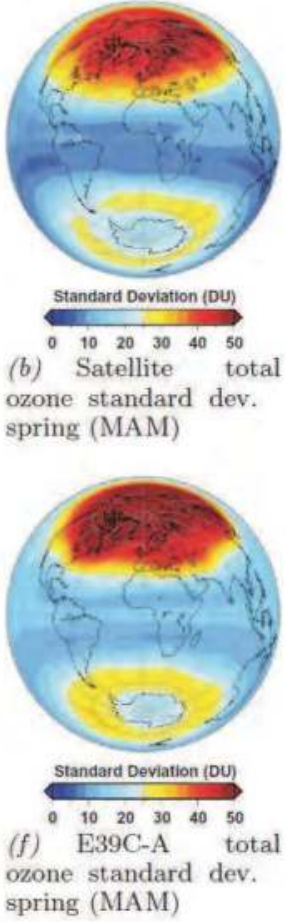
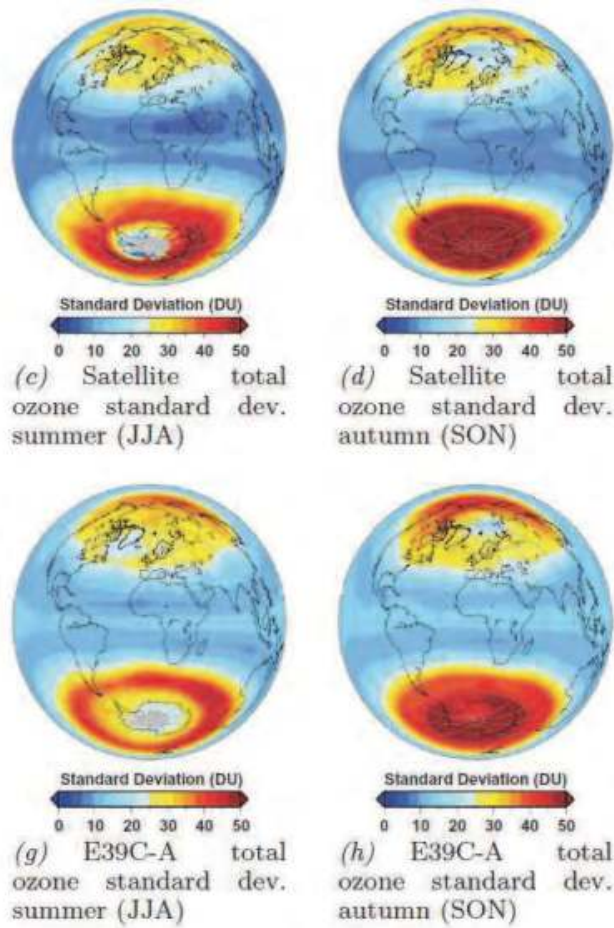

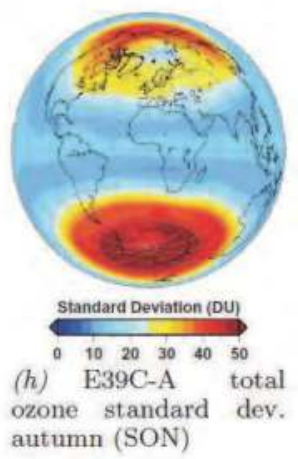

Fig. 9. Seasonal mean values of total ozone standard deviations (June 1995 to May 2008) from GOME/SCIAMACHY/GOME-2 satellite instruments (top) and the E39CA simulation (bottom) (Figure 7 in Loyola et al., 2009).

tropospheric CFC content has been observed (WMO, 2011). Consequently, a slight decrease in stratospheric chlorine concentrations has also been detected for several years now. However, due to the long lifetimes of CFCs in the atmosphere, it will take until the middle of this century for the stratosphere's chlorine content to go back to values resembling those observed in the 1960ies. Therefore, it is expected that the strong chemical ozone depletion observed over the past three decades will decrease in the near future. In this context, a solid assessment of the timing of the ozone layer recovery and particular the closure of the ozone hole is not a trivial task since the future evolution of the ozone layer is affected by several processes. In particular ongoing climate change will have an influence on atmospheric dynamics (including the transport of ozone) and ozone chemistry (via temperature changes). CCMs are suitable tools to perform prognostic studies regarding the evolution of stratospheric ozone content, because they are considering the complex interactions of dynamical, physical and chemical processes.

Based on prognostic studies with CCMs it is expected that the ozone layer will build up again in the next decades and that the ozone hole over Antarctica will be closed (see Chapter 3 in WMO, 2011; Chapter 9 in SPARC CCMVal, 2010). Figure 10 shows an example of the temporal evolution of total ozone deviations regarding a mean ozone value (1995-2009) for the near global mean (i.e. global mean values neglecting polar regions). Looking into the past it is obvious that E39CA is able to reproduce seasonal and interannual fluctuations in a 
sufficient manner, although the amplitudes of ozone anomalies are slightly underestimated. Model data and data derived from satellite observations clearly show the signal of the 11year solar cycle. The absolute minimum ozone values observed in years 1993-95, which are caused by the eruption of the volcano Pinatubo, are not adequately reproduced by E39CA. The simulated increase in stratospheric ozone amount after year 2010 is a direct consequence of the prescribed decrease of stratospheric chlorine content.

The speed at which the ozone layer will rebuild in future depends on a range of other factors, however. Rising atmospheric concentrations of radiatively active gases (such as $\mathrm{CO}_{2}$, $\mathrm{CH}_{4}$ and $\mathrm{N}_{2} \mathrm{O}$ ) do not just cause the conditions in the troposphere to change (i.e. the greenhouse effect warms the troposphere), but also in the stratosphere which cools down with increasing $\mathrm{CO}_{2}$ concentrations. The regeneration of the ozone layer thus takes place under atmospheric conditions different to those prevailing during the ozone depletion processes of recent decades. Due to climate change, it is highly unlikely that the ozone layer will return to exactly the way it was before the time of increased concentrations of ozonedepleting substances.

Total Ozone Deviation $\left(60^{\circ} \mathrm{N}-60^{\circ} \mathrm{S}\right)$

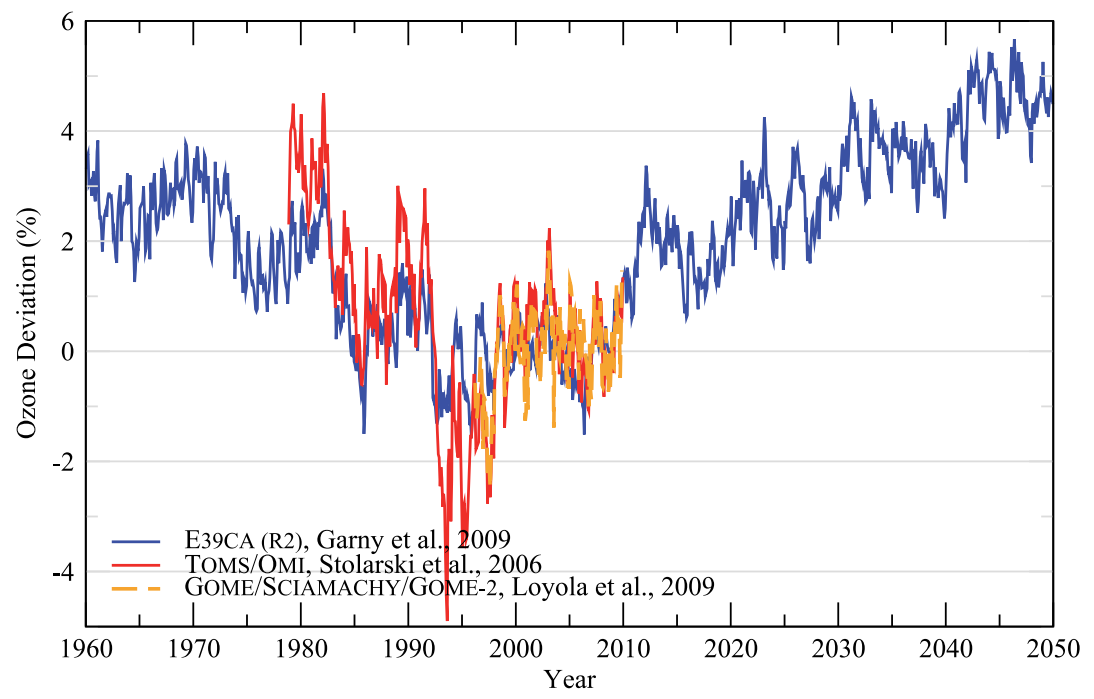

Fig. 10. Average deviations of the total ozone column (in \%) for the region between $60^{\circ} \mathrm{N}$ and $60^{\circ} \mathrm{S}$. The mean annual cycle for the period 1995-2009 was subtracted in each case. The orange and red curves represent data obtained from satellite instruments (TOMS, GOME, SCIAMACHY and GOME-2). The blue curve shows results from a numerical simulation (R2) using a chemistry-climate model (E39CA).

Due to further increasing greenhouse gas concentrations, global atmospheric temperatures will continue to change over the coming decades, i.e. it is expected that the troposphere will continue to warm up and that the stratosphere will cool down further due to radiation effects. In addition, it must also be taken into account that, due to the expected build-up of the ozone layer, stratospheric ozone heating rates (absorption of solar ultraviolet radiation by ozone) will increase again, to some extent counteracting the increased cooling due to 
rising greenhouse gas concentrations. However, as the ozone concentration depends largely on the background temperature, there will be some feedback. Since climate change also involves a change in the stratosphere's dynamics, "dynamic" heating of the stratosphere can also occur, depending on the time of year and place, which leads to local stratospheric heating, rather than cooling. That's why it is important to take the interactions between chemical, physical and dynamic processes into account, both for the interpretation of observed changes in the ozone layer and for prognostic studies. It must be always considered that ozone and climate connections are influencing each other in both directions. Therefore, estimates of future stratospheric ozone concentration developments and climate change are not trivial and bring uncertainties with them.

Future prognostics with CCMs also clearly indicate that ozone regeneration will be faster in some areas than in others, where it's quite possible that the recovery of the ozone layer will be delayed (Chapter 3 in WMO, 2011). The results of E39CA also show that the regeneration of the ozone layer will vary from region to region and does not represent a simple reversal of the depletion observed over recent years. Examples are presented in Figure 11, showing the evolution of the stratospheric ozone layer in the Northern and Southern polar regions.

In contrast to Figure 10, only the data for respective spring months are shown when ozone depletion maximises. First of all, E39CA reproduces nicely the different evolution of the ozone layer in the Northern and Southern Hemisphere in the past showing a more pronounced thinning of the ozone layer in the Southern Hemisphere due to the formation of the ozone hole. Interannual fluctuations are well captured by E39CA in the Northern Hemisphere while they are underestimated in the Southern Hemisphere. Here, for example, the model does not create dynamical situations leading to weak polar vortices in late winter and early spring and therefore higher ozone values as particularly observed in 1988 and 2002 (see also Figure 4). Obviously, the recreation speed of the ozone layer is different in the Northern and in the Southern Hemisphere: In the Northern Hemisphere ozone values found in the 1960ies and 1970ies are reached again around 2030 and further increase afterwards. In the Southern Hemisphere the 2050-values are still below the values found in the 1960ies (see also Figure 12). Looking again to Figure 10, here the ozone values after 2030 are also higher than before 1980 .

What is the reason for this different behaviour in different stratospheric regions? Due to the continued increase in greenhouse gas concentrations in the atmosphere, the stratosphere will further cool down, resulting in faster ozone-layer regeneration especially in the middle and upper stratosphere. Here, lower temperatures slow down ozone destroying (temperature depending) chemical reactions. In the lower polar stratosphere, in particular in the Southern Hemisphere, the rebuilding of the ozone layer may slow down during spring. There, lower temperatures lead to an increased formation of polar stratospheric clouds (PSCs), which are the necessary prerequisite to start ozone depletion. On the other hand, climate change will affect ozone transport to higher latitudes. E39CA predict enhanced transport of stratospheric air masses from tropical to extra-tropical regions. Caused by the isolation of the Southern Hemisphere polar stratosphere (originated by the high zonal wind speed there; see Section 1.2) this change does not lead to a faster closure of the ozone hole (see also Figure 12); contrastingly, in the Northern Hemisphere the transport of ozone rich air towards polar latitudes is intensified, leading to a quicker back formation of the ozone layer. Overall, model simulations indicate that the ozone layer is expected to recreate faster in the Arctic than in the Antarctic stratosphere. 
Total Ozone Deviation $\left(90^{\circ} \mathrm{N}-60^{\circ} \mathrm{N}\right)$ in FMA

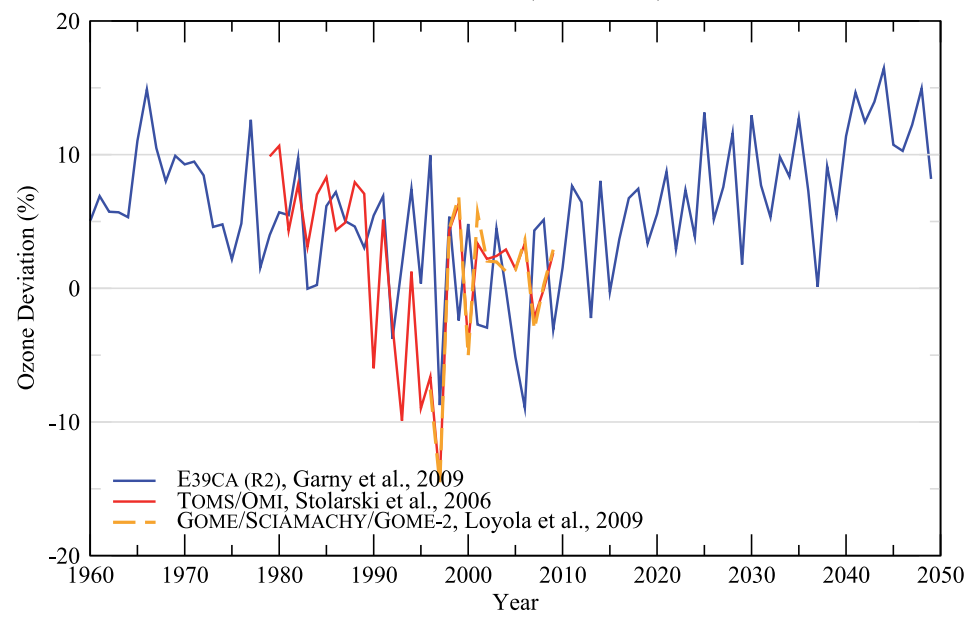

Total Ozone Deviation $\left(60^{\circ} \mathrm{S}-90^{\circ} \mathrm{S}\right)$ in SON

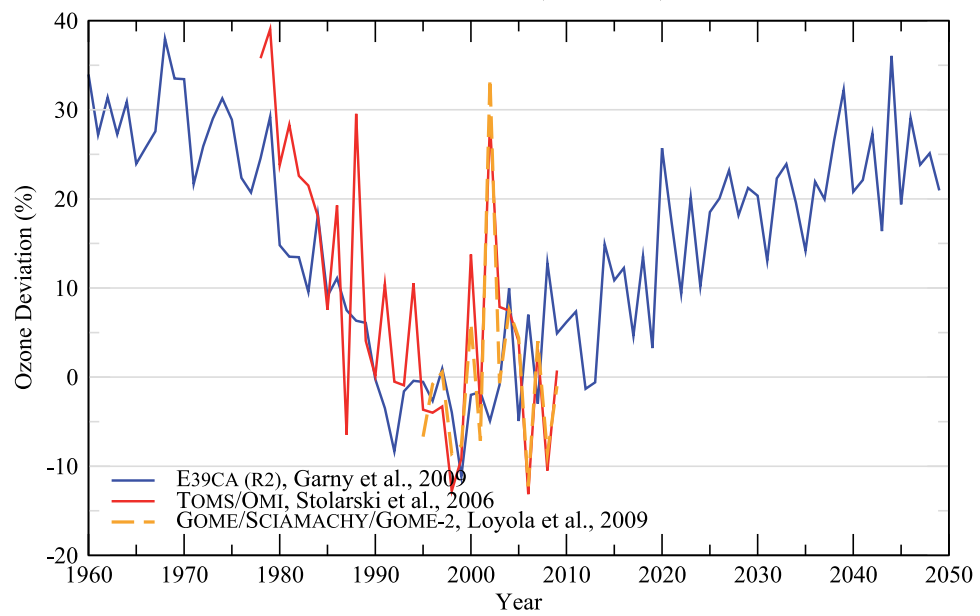

Fig. 11. As Figure 10, but now for the polar regions (top: Northern Hemisphere for months February, March, and April; bottom: Southern Hemisphere for months September, October, and November). Deviations are given with regard to the mean value of the period 1995-2009 (in \%) for the region between $60^{\circ}$ and $90^{\circ}$. Notice the different scales on the y-axis.

Figure 12 provides another view of the temporal evolution of the ozone hole as it is simulated by E39CA from the 1960ies to the 2040ies. Here, decadal mean total ozone values for October are presented. Respective mean values derived from satellite instruments are shown for comparison (notice again that the satellite and the CCM plots use different colour bars representing Dobson Units.) These images of simulated total ozone columns also indicate that the closure of the ozone hole will be delayed regarding the prescribed temporal decrease of the stratospheric chlorine content, i.e. will be not completed before 2050 (see also lower part of Figure 11). 


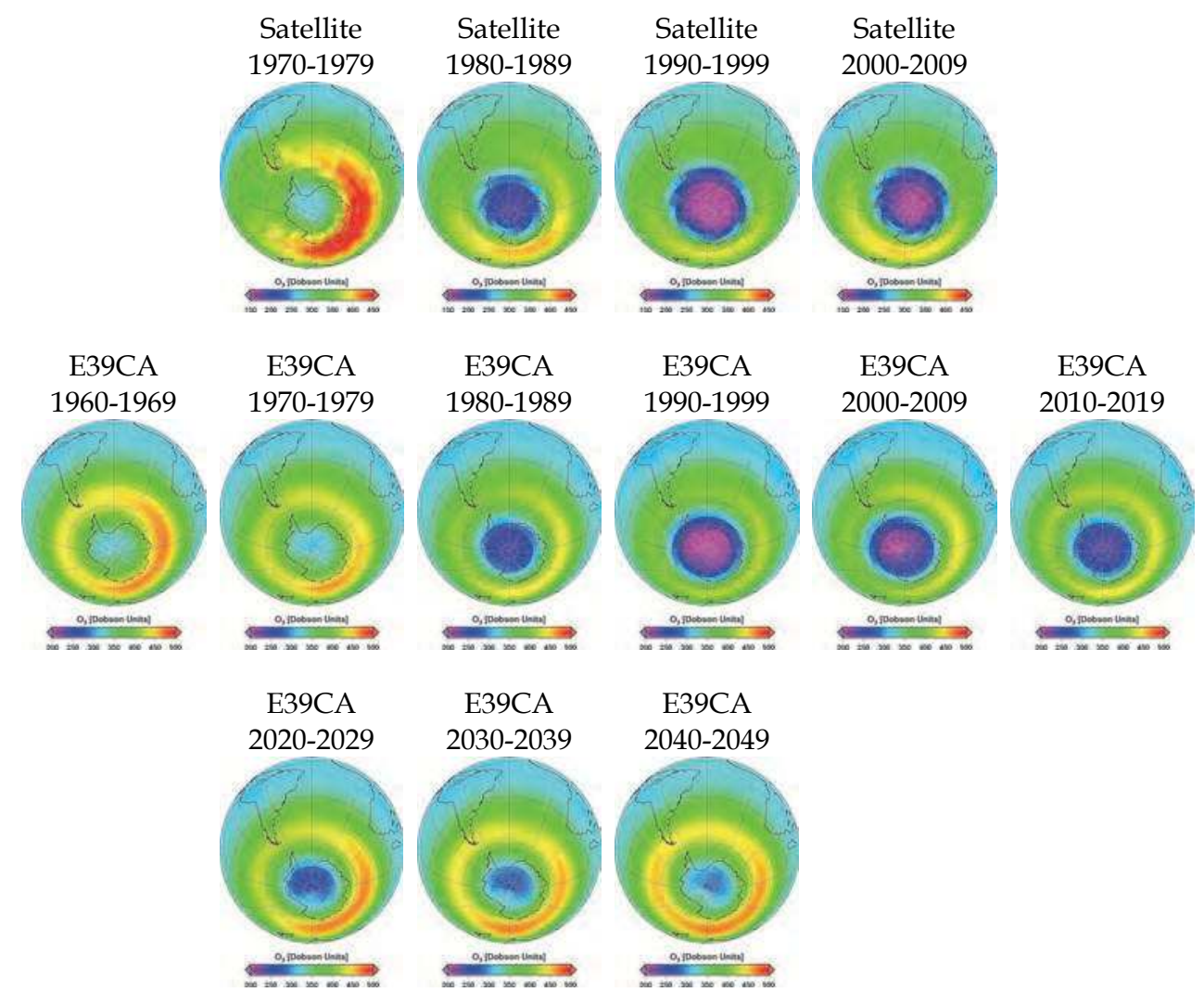

Fig. 12. Decadal evolution of the ozone hole in October (monthly mean value) derived from satellite measurements (TOMS, GOME, SCIAMACHY, GOME-2) from 1970 to 2009 and the simulation with the CCM E39CA from 1960 until 2049.

\section{Discussion of uncertainties and conclusion}

Obviously, reliable estimates of the future evolution of atmospheric behaviour are difficult because of strong interactions between physical, dynamical and chemical processes which, moreover, are expected to be modified in a future climate with enhanced greenhouse gas concentrations.

Further uncertainties must be taken into account regarding the future development of both the stratospheric ozone layer and the climate. The future development of stratospheric water vapour concentrations is currently highly uncertain. Prognostic studies with numerical models indicate that tropospheric water vapour concentrations would increase with increasing temperatures in the troposphere, which would also enhance the amount of water vapour being transported from the troposphere into the lower tropical stratosphere (e.g. WMO, 2007). Higher stratospheric water vapour concentrations could lead to an increased PSC-forming potential in the polar regions during the winter months and thus enhance the ozone depletion potential. As water vapour is also an important greenhouse gas, changes of 
atmospheric concentrations would affect atmospheric radiation balance. Stratospheric water vapour concentrations would also increase with rising methane $\left(\mathrm{CH}_{4}\right)$ concentration (e.g. caused by rice cultivation, intensive livestock farming, thawing of permafrost soils) due to oxidation of $\mathrm{CH}_{4}$, which would itself increase ozone production in the lower stratosphere. On the other hand, rising $\mathrm{CH}_{4}$ concentrations would bind reactive chlorine in the atmosphere. However, $\mathrm{CH}_{4}$ is also an important greenhouse gas. Therefore, higher atmospheric $\mathrm{CH}_{4}$ concentrations would influence both the climate and atmospheric chemistry. A further rise in atmospheric nitrous oxide $\left(\mathrm{N}_{2} \mathrm{O}\right)$ concentrations would increase the amount of atmospheric nitrogen oxides, thus decreasing the ozone content of the middle and upper stratosphere. $\mathrm{N}_{2} \mathrm{O}$ (although known as laughing gas) stems from both natural (for example oceans and tropical forests) and anthropogenic sources (for example emissions from cultivated soil, industrial processes, the combustion of fossil fuels, biomass, and biofuels). $\mathrm{N}_{2} \mathrm{O}$ emissions near the Earth's surface are the most important source of nitrogen oxides in the stratosphere. $\mathrm{N}_{2} \mathrm{O}$ is also a key greenhouse gas. This is another example which nicely illustrates the close relationship between problems associated with climate change and those relating to changes in the stratospheric ozone layer. Regulating the atmospheric $\mathrm{N}_{2} \mathrm{O}$ content in the atmosphere is not just important for protecting the Earth's climate, but also for the future evolution of the stratospheric ozone layer. A reduction in $\mathrm{N}_{2} \mathrm{O}$ emissions would both lower the anthropogenic greenhouse effect and positively influence the recovery of the ozone layer.

To summarise: Clearly, natural effects such as the variability of solar radiation and particle emissions that are due to strong volcanic eruptions influence the stratospheric ozone concentration. Internal fluctuations of stratospheric circulation affect the thermal structure of the stratosphere and air mass transport. Chemical production and depletion of ozone are determined by photochemical processes, homogeneous gas-phase reactions, and heterogeneous chemistry on the surface of particles (aerosols and PSCs). Understanding atmospheric processes and the interconnections between the various processes is made even more difficult by the fact that atmospheric conditions change over the long term owing to increased greenhouse gas concentrations. Climate change influences the overall stratospheric ozone production (i.e. the sum of ozone depletion and production) both directly and indirectly, and thus determines the rate of ozone regeneration, which will vary with altitude and latitude. Furthermore, changes in stratospheric circulation can potentially modify the development of the ozone layer in the $21^{\text {st }}$ century. For example, a stronger meridional circulation in an atmosphere with increased greenhouse gas concentrations could cause the stratospheric wind systems to change during the winter months, thus for example resulting in decreased zonal wind speeds. This could lead to higher mean stratospheric temperatures in the polar regions and thus less PSCs.

The climate-chemistry connections presented in this chapter clearly demonstrate that in assessing atmospheric changes it is not enough to look at the processes independent of each other. Changes in climate and in the chemical composition of the atmosphere are closely interrelated, sometimes in very complex ways. Therefore, surprising developments cannot be ruled out in the future, either.

\section{Acknowledgment}

Thanks to NASA for the provision of the TOMS satellite data, ESA/DLR for the provision of the GOME and SCIAMACHY data, O3M-SAF/EUMETSAT/DLR for the provision of the GOME-2 data. We would like to thank colleagues from BIRA-IASB (Belgium), DLR (Germany), RT Solutions Inc. (USA) and AUTH (Greece) for their work on ozone retrieval 
algorithms from the European satellites and corresponding geophysical validation. Special thanks to the DLR colleagues, $M$. Coldewey-Egbers for merging the GOME/SCIAMACHY/GOME-2 measurements and providing the ozone deviation data, and A. Stenke and H. Garny for the development of the E39CA model and providing the simulation data.

This work was partially supported by the ESA Climate Change Initiative project on Ozone (Ozone CCI).

\section{References}

Baldwin, M.P.; Gray, L.J.; Dunkerton, T.J.; Hamilton, K.; Haynes, P.H.; Randel, W.J.; Holton, J.R.; Alexander, M.J.; Hirota, I.; Horinouchi, T.; Jones, D.B.A.; Kinnersley, J.S.; Marquardt, C.; Sato, K.; and Takahashi, M. (2001). The Quasi-Biennial Oscillation, Rev. Geophys., Vol. 39, 179-229

Bates, D.R.; and Nicolet, M. (1950). The photochemistry of atmospheric water vapor, J. Geophys Res., Vol. 55, 301-327

Burrows, J.; Weber, M; Buchwitz, M; Rozanov, V.; Ladstätter-Weißenmayer, A.; Richter, A.; DeBeek, R.; Hoogen, R.; Bramstedt, K.; Eichmann, K.; Eisinger, M.; Perner, D. (1999). The Global Ozone Monitoring Experiment (GOME): Mission Concept and First Scientific Results, J. Atmos. Sci., Vol. 56, No. 2, pp. 151-175

Chapman, S. (1930). A theory of upper-atmosphere ozone, Mem. Roy. Meteor. Soc., Vol. 3, pp. 103-125

Crutzen, P.J. (1971). Ozone production rates in an oxygen-hydrogen-nitrogen atmosphere, J. Geophys. Res., Vol. 76, 7311-7327

Dameris, M. (2010). Climate change and atmospheric chemistry: How will the stratospheric ozone layer develop?, Angew. Chem. Int. Ed., Vol. 49, pp. 8092-8102, doi: 10.1002/anie. 201001643

Garny, H.; Dameris, M.; Stenke, A. (2009). Impact of prescribed SSTs on climatologies and long-term trends in CCM simulations, Atmos. Chem. Phys., Vol. 9, pp. 6017-6031

IPCC, Intergovernmental Panel on Climate Change (2001). Climate Change 2001: The Scientific Basis, Cambridge University Press, New York, USA

IPCC, Intergovernmental Panel on Climate Change (2007). Climate Change 2007: The Physical Basis 2007, ISBN 978-0-521-70596-7, pp. 996

Johnston, H.S. (1971). Reduction of stratospheric ozone by nitrogen oxide catalysts from SST exhaust, Science, Vol. 173, 517-522

Johns, T.C.; Durman, C.F.; Banks, H.T.; Roberts, M.J.; McLaren, A.J.; Ridley, J.K.; Senior, C.A.; Williams, K.D.; Jones, A.; Rickard, G.J.; Cusack, S.; Ingram, W.J.; Crucifix, M.; Sexton, D.M.H.; Joshi, M.M.; Dong, B.-W.; Spencer, H.; Hill, R.S.R.; Gregory, J.M.; Keen, A.B.; Pardaens, A.K.; Lowe, J.A.; Bodas-Salcedo, A.; Stark, S.; and Searl, Y. (2006). The New Hadley Centre Climate Model (HadGEM1): Evaluation of Coupled Simulations, I. Climate, Vol. 19, 1327-1353

Land C.; Feichter, J.; and Sausen, R. (2002). Impact of vertical resolution on the transport of passive tracers in the ECHAM4 model, Tellus B, 54, 344-360

Loyola, D.; Coldewey-Egbers, M.; Dameris, M.; Garny, H.; Stenke, A.; Van Roozendael, M.; Lerot, C.; Balis, D. \& Koukouli M. (2009). Global long-term monitoring of the ozone layer - a prerequisite for predictions, Int. J. of Remote Sensing, Vol. 30, No. 15, pp. 4295-4318

Loyola, D.; Koukouli, M.; Valks, P.; Balis, D.; Hao, N.; Van Roozendael, M.; Spurr, R.; Zimmer, W.; Kiemle, S.; Lerot, C.; Lambert, J.-C. (2011). The GOME-2 total column 
ozone product: Retrieval algorithm and ground-based validation, J. Geophys. Res., Vol. 116, D07302, doi: 10.1029/2010JD014675

Molina, M.J.; and Rowland, F.S. (1974). Atomic-catalysed destruction of ozone, Nature, Vol. 249, 810-812

Rayner, N.A.; Parker, D.E.; Horton, E.B.; Folland, C.K.; Alexander, L.V.; Rowell, D.P.; Kent, E.C.; and Kaplan, A. (2003). Global Analyses of sea surface temperatures, sea ice, and night marine air temperature since the late nineteenth century, J. Geophys. Res., Vol. 108, 4407, doi: 10.1029/2002JD002670

Roeckner, E.; Arpe, K.; Bengtsson, L.; Christoph, M.; Claussen, M.; Dümenil, L.; Esch, M.; Giorgetta, M.; Schlese, U.; and Schulzweida, U. (1996). The atmospheric general circulation model ECHAM-4: Model description and simulation of present-day climate, Report No. 218, Max-Planck-Institut für Meteorologie, Hamburg

Solomon, S.; Garcia, R.R.; Rowland, F. S.; and Wuebbles, D. J. (1986). On the Depletion of Antarctic Ozone, Nature, Vol. 321, 755-758

SPARC CCMVal (2010). SPARC Report on the Evaluation of Chemistry-Climate Models, V. Eyring, T.G. Shepherd, D.W. Waugh (Eds.), SPARC Report No. 5, WCRP-132, WMO/TD-No. 1526, http://www.atmosp.physics.utoronto.ca/SPARC

Steil, B., Dameris, M.; Brühl, C.; Crutzen, P.J.; Grewe, V.; Ponater, M.; and Sausen, R. (1998). Development of a chemistry module for GCMs: first results of a multiannual integration, Ann. Geophysicae, Vol. 16, 205-228

Stenke, A.; Dameris, M.; Grewe, V.; and Garny, H. (2009). Implications of Lagrangian transport for simulations with a coupled chemistry-climate model, Atmos. Chem. Phys., Vol. 9, 5489-5504.

Stolarski, R.; Frith, S. (2006). Search for evidence of trend slow-down in the long-term TOMS/SBUV total ozone data record: the importance of instrument drift uncertainty, Atmos. Chem. Phys., Vol. 6, 4057-4065

Van Roozendael, M.; Loyola, D.; Spurr, R.; Balis, D.; Lambert, J-C.; Livschitz, Y.; Valks, P.; Ruppert, T.; Kenter, P.; Fayt, C.; Zehner, C. (2006). Ten years of GOME/ERS-2 total ozone data: the new GOME Data Processor (GDP) Version 4: I. Algorithm Description, J. Geophys.Res., Vol. 111, D14311

WMO/UNEP, World Meteorological Organization, Scientific Assessments of Ozone Depletion: 1991 (1992). Global Ozone Research and Monitoring Project, Report No. 25, Geneva

WMO/UNEP, World Meteorological Organization, Scientific Assessments of Ozone Depletion: 1994 (1995). Global Ozone Research and Monitoring Project, Report No. 37, Geneva

WMO/UNEP, World Meteorological Organization, Scientific Assessments of Ozone Depletion: 1998 (1999). Global Ozone Research and Monitoring Project, Report No. 44, Geneva

WMO/UNEP, World Meteorological Organization, Scientific Assessments of Ozone Depletion: 2002 (2003). Global Ozone Research and Monitoring Project, Report No. 47, Geneva, pp. 498

WMO/UNEP, World Meteorological Organization, Scientific Assessments of Ozone Depletion: 2006 (2007). Global Ozone Research and Monitoring Project, Report No. 50, Geneva, pp. 572

WMO/UNEP, World Meteorological Organization, Scientific Assessments of Ozone Depletion: 2010 (2011). Global Ozone Research and Monitoring Project, Report No. 52, Geneva, pp. 516

Wolfsy, S.C.; Mc Elroy, M.B.; Yung, Y.L. (1975). The chemistry of atmospheric bromine, Geophys. Res. Lett., Vol. 2, 215-218 


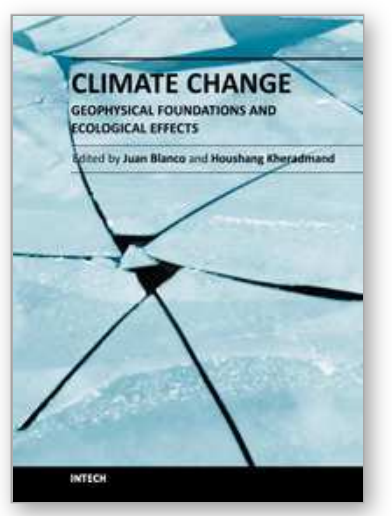

\author{
Climate Change - Geophysical Foundations and Ecological Effects \\ Edited by Dr Juan Blanco
}

ISBN 978-953-307-419-1

Hard cover, 520 pages

Publisher InTech

Published online 12, September, 2011

Published in print edition September, 2011

This book offers an interdisciplinary view of the biophysical issues related to climate change. Climate change is a phenomenon by which the long-term averages of weather events (i.e. temperature, precipitation, wind speed, etc.) that define the climate of a region are not constant but change over time. There have been a series of past periods of climatic change, registered in historical or paleoecological records. In the first section of this book, a series of state-of-the-art research projects explore the biophysical causes for climate change and the techniques currently being used and developed for its detection in several regions of the world. The second section of the book explores the effects that have been reported already on the flora and fauna in different ecosystems around the globe. Among them, the ecosystems and landscapes in arctic and alpine regions are expected to be among the most affected by the change in climate, as they will suffer the more intense changes. The final section of this book explores in detail those issues.

\title{
How to reference
}

In order to correctly reference this scholarly work, feel free to copy and paste the following:

Martin Dameris and Diego Loyola (2011). Chemistry-Climate Connections - Interaction of Physical, Dynamical, and Chemical Processes in Earth Atmosphere, Climate Change - Geophysical Foundations and Ecological Effects, Dr Juan Blanco (Ed.), ISBN: 978-953-307-419-1, InTech, Available from:

http://www.intechopen.com/books/climate-change-geophysical-foundations-and-ecological-effects/chemistryclimate-connections-interaction-of-physical-dynamical-and-chemical-processes-in-earth-atmo

\section{INTECH}

open science | open minds

\section{InTech Europe}

University Campus STeP Ri

Slavka Krautzeka 83/A

51000 Rijeka, Croatia

Phone: +385 (51) 770447

Fax: +385 (51) 686166

www.intechopen.com

\section{InTech China}

Unit 405, Office Block, Hotel Equatorial Shanghai

No.65, Yan An Road (West), Shanghai, 200040, China

中国上海市延安西路65号上海国际贵都大饭店办公楼 405 单元

Phone: +86-21-62489820

Fax: $+86-21-62489821$ 
(C) 2011 The Author(s). Licensee IntechOpen. This chapter is distributed under the terms of the Creative Commons Attribution-NonCommercialShareAlike-3.0 License, which permits use, distribution and reproduction for non-commercial purposes, provided the original is properly cited and derivative works building on this content are distributed under the same license. 